\title{
THE IMPORTANCE OF EPIDEMIOLOGY IN OPTOMETRY
}

\author{
BY \\ ORIAHI, M. O. \\ COMMON SIGHT LTD, \\ 82, OLD OJO ROAD, KUJE-AMUWO, LAGOS, \\ LAGOS STATE, NIGERIA. \\ EMAIL: mreenoriahi@yahoo.com
}

\begin{abstract}
7 pidemiology is the study of the distribution and determinants of health-related states or events in specified populations, and the application of this study to the control of health problems. Epidemiology aims to describe the distribution and magnitude of health and disease problems, identify etiological factors in the pathogenesis of disease, and provide the data essential to the planning, implementation and evaluation of services for the prevention, control and treatment of disease and to the setting up of priorities among those services. Optometrists are the primary health care practitioners of the eye and visual system who provide comprehensive eye and vision care, which includes refraction and dispensing, the detection/diagnosis and management of disease in the eye, and rehabilitation of conditions of the visual system. Refractive error is amongst the most common causes of blindness and visual impairment; it is also the easiest to "cure". Refractive error can be simply diagnosed, measured and corrected, and the provision of spectacles is an extremely cost-effective intervention, providing immediate correction of the problem. Refractive care provides excellent access to the population for screening of more serious eye problems, such as cataracts and diabetes. Preventable blindness is one of our most tragic and wasteful global problems. Optometry is an essential part of the team that will eliminate this tragedy, by understanding global eye care needs and delivering effective and sustainable vision care to people in need, thereby ensuring their fundamental right to sight.
\end{abstract}

KEYWORDS: Optometry, epidemiology, blindness, refractive error, frequency, distribution.

\section{INTRODUCTION}

Epidemiology is the study of the distribution and determinants of health-related states or events in specified populations, and the application of this study to the control of health problems (Last 1988) ${ }^{1}$. Four key words in epidemiology

Frequency............. numbers

Distribution........... where, when and how

Determinants........... etiological and risk factors

Deterrents.......... controls put in place

The aims of epidemiology are

1. to describe the distribution and magnitude of health and disease problems in human populations

2. to identify etiological factors (risk factors) in the pathogenesis of disease

3. To provide the data essential to the planning, implementation and evaluation of services for the prevention, control and treatment of disease and to the setting up of priorities among those services (IEA).

The ultimate aim of epidemiology is to eliminate or reduce the health problem or its consequences; and to promote the health and wellbeing of society as a whole.

\section{EPIDEMIOLOGICALAPPROACH}

The epidemiological approach to problems of health and disease is based on two major foundations:

a. asking questions

b. Making comparisons

\section{QUESTIONS RELATED TO HEALTH EVENTS}

a. What is the event? (the problem)

b. What is its magnitude?

c. Where did it happen?

d. When did it happen?

e. Who are affected?

f. Why did it happen?

\section{QUESTIONS RELATED TO HEALTH ACTION}

a. What can be done to reduce this problem and its consequences?

b. How can it be prevented in the future?

c. What actions should be taken by the community? By the health services? By other 
sectors? Where and for whom these activities be carried out?

d. What resources are required? How are the activities to be organized?

e. What difficulties may arise, and how might they be overcome?

Answer to the above questions may provide clues to disease etiology, and help you to guide planning and evaluation.

Descriptive Epidemiology you are describing the outcome based on that person. There are several variables to describe a person:

Age: disease varies with age. Presbyopia, chronic degenerative diseases are more in the elderly. Severity of disease also varies with age.

$\square$ Sex (gender): some diseases are sex specific e.g. color blindness

\section{Marital status}

Genotype/ blood group: sicklers may be more prone to have retinal vein occlusion.

$\square$ Occupation: the type of job you do, for example, a welder is prone to foreign bodies.

$\square$ Race: temperature seems to affect age of onset of presbyopia.

$\square$ Education

Religion

Optometrists are the primary health care practitioners of the eye and visual system who provide comprehensive eye and vision care, which includes refraction and dispensing, the detection/diagnosis and management of disease in the eye, and rehabilitation of conditions of the visual system ${ }^{2}$. Preventable blindness is one of our most tragic and wasteful global problems.

Optometry is an essential part of the team that will eliminate this tragedy, by understanding global eye care and delivering effective and sustainable vision care to people in need, thereby ensuring their fundamental right to sight ${ }^{3}$. The global magnitude of refractive errors is not reliably known. There is a large variation in prevalence (by age, gender, and race). Lack of epidemiological data on the magnitude of uncorrected visually disabling refractive error in Nigeria is a big challenge to all of us.

\section{VISION 2020: THE RIGHT TO SIGHT}

This is a global initiative to reduce avoidable (preventable and curable) blindness by the year 2020. Nigeria is also committed to this initiative.
The plan of action for the country has been developed with the following main features:
1. Target diseases are
a. Cataract
b. Trachoma
c. Onchocerciasis
d. Childhood blindness
e. Refractive error
f. Low vision.

They have been selected not only because of the burden of blindness that they represent but also, because of the feasibility and affordability of interventions to prevent and treat these conditions.

2. Human resources development as well as infrastructure and technology development at various levels of the health system. The proposed three tier structure includes Vision 2020 specialists, mid level personnel and community level.

\section{NIGERIAN SITUATION (FMOH) ${ }^{4}$}

The causes of blindness in Nigeria are shown below:
Cataract accounts for $50 \%$
Glaucoma $16 \%$
Corneal opacity $12 \%$
Optic atrophy $3 \%$
Refractive error $1 \%$
Macular degeneration $<1 \%$
And other causes $18 \%$

\section{KEYFACTS}

Blindness does not only mean complete loss of sight, but also includes those who cannot see properly from a distance of 3 meters and therefore cannot manage their day-to-day activities on their own.

$\square$ More than $90 \%$ of the world's blind live in low and middle income countries, $75 \%$ of the blindness can either be prevented or treated. Most of these people suffer needlessly as their blindness is avoidable.

Vision 2020 is a global initiative for eliminating blindness from those causes which are preventable or treatable.

The first ever national survey of blindness and low vision was undertaken from 2005-2007.

$\square$ More than a million Nigerians are blind. Half of them in the North West and East.

More than 3 million have inadequate vision, in addition to the million blind. 
More than half of those with inadequate vision can benefit greatly by a pair of spectacles.

Optometrists have had little opportunity to take part in the front line elimination of four of the major, preventable blindness producing conditions targeted by Vision 2020. The realization of the impact of uncorrected refractive error has provided the opportunity for optometry to play a major part in alleviating vision loss for those most in need.

\section{OPTOMETRIST'S ROLE IN CORRECTING REFRACTIVE ERROR}

The good news is that while refractive error is amongst the most common causes of blindness and visual impairment, it is also the easiest to "cure". Refractive error can be simply diagnosed, measured and corrected, and the provision of spectacles is an extremely cost- effective intervention, providing immediate correction of the problem.

Throughout the world optometry has been the major provider of vision correction, but usually from a private practice setting. Public health optometry has not reached the communities that are in most need in any organized way. Despite this, on their own initiative, thousands of private optometrists world wide have regularly visited communities in need to provide vision care and dispense spectacles.

\section{WHAT IS NEEDED?}

The way to eliminate uncorrected refractive error is through the development of all these aspects of a self- sustaining system, including personnel to provide eye care services; and spectacles to correct vision.

Trained eye personnel + Affordable spectacles $=$ PEOPLE WHO CAN SEE!

In most developed countries the optometrist to population ratio is approximately $1: 10,000^{3}$. However, in developing countries the ratio is $1: 600,000^{3}$ and much worse in many rural areas, up to millions of people per optometrist. This lack of practitioners is the main reason for high rate of vision problems due to uncorrected refractive errors in developing countries. The "blindness" rate in many developing countries, especially in Africa, is 7 times higher, at $1.4 \%$, than in developed countries ${ }^{5}$.

\section{OPTOMETRY AS PART OF THE EYE CARE} TEAM

Refractive care provides excellent access to the population for screening of more serious eye problems, such as cataracts and diabetes. Primary care screening by optometrists and eye care workers, with optometrists taking care of the more immediate interventions required and referral for more complicated care is "classical" health care delivery.

One effective current model, developed by the LV Prasad Eye Institute in Hyderabad, India, for the efficient and cost- effective delivery of eye care is a community eye care 'team'. ${ }^{15}$ For every $1,000,000$ people the team has:
1 Ophthalmologist
4 Optometrists
8 Eye care workers
8 Ophthalmic assistants
16 Ophthalmic Nurses

\section{THE ROLE OF RESEARCH}

As the previous statistics show, there is a significant problem to be faced in addressing uncorrected refractive error. But understanding the scope of the problem, and most importantly, planning how to solve it, requires much more information than these simple numbers. Adequate prevalence data are necessary to determine the regions, population groups and age cohorts most in need of intervention, and also, to provide the basis from which intervention in the future can be evaluated.

As part of the front line of the eye care team, optometry has a role to play in research and collecting the data needed to design eye care intervention, both in refractive error and for other eye care needs. Optometry can significantly contribute to the understanding of:

World wide blindness and impaired vision the burden and its effects

Health care planning

Service delivery

Outcomes of intervention.

\section{REFRACTIVE ERROR STUDY IN CHILDREN}

A series of studies around the world have begun to fill in the gaps in our knowledge of the burden of blindness and impaired vision in children caused by refractive error. The studies addressed the variation of refractive error with age, gender, race, and geographic region, the extent to 
which it is being corrected, and how the prevalence is changing over time. The Refractive Error Studies in children (RESC) have so far been conducted in Nepal, China, Chile and India, using population- based, cross sectional sampling, consistent definitions and a common methodology. ICEE is currently conducting the RESC study in Kwazulu Natal, South Africa in conjunction with the National Eye Institute and WHO, and sponsored by CBM International, Sight Savers International and ICEE. At the completion of the Africa study, data will have been collected from approximately 30,000 children worldwide.

\section{SELF SUSTAINABILITY, REFRACTIVE ERROR AND OPTOMETRY ${ }^{5}$}

Two other important contributions that optometry and the optical industry can make to the worldwide fight to eliminate avoidable blindness and impaired vision due to refractive error are:

$\square$ Developing the logistics and economics of self sustaining eye care at the community and institutional levels

Mobilizing worldwide resources to develop models and create the educational and delivery infrastructure for refractive and general vision care.

\section{CONCLUSION}

It should not be necessary for any child to struggle in school, to learn with uncorrected refractive error. Nor should any older person be called upon to spend thirty or forty years without glasses, to see, read, or sew, or to manage a job ${ }^{3}$. Optometry and the optical industry in its broadest sense should be able to find the financial resources to give this simplest gift of sight.

Preventable blindness is one of our most tragic and wasteful global problems. Optometry is an essential part of the team that will eliminate this tragedy, by understanding global eye care needs and delivering effective and sustainable vision care to people in need, thereby ensuring their fundamental right to sight.

\section{REFERE N C E S}

1. Park, K. (2007): Preventive and Social Medicine. $19^{\text {th }}$ Edn. Banarsidas Bhanot Publishers, India, 362pp.

2. Smith, D. P. (Guest Editorial): The $75^{\text {th }}$ anniversary of the World Council of Optometry. Clin. Exp. Optom, 85: 4: 210-213.

3. Holden, B. A. and Serge R. (2002): The Role of
Optometry in Vision 2020. J. Comm. Eye Hlth, 15(43): 33-36.

4. FMOH, The Nigeria national survey, 2008

5. Naidoo, K. (2008): Optometry as part of Vision 2020: global perspective. Global initiative to eliminate avoidable blindness by 2020 ; WHO bulletin. 